\title{
J-curve relationship between long term glycemic control and mortality in diabetic patients with acute myocardial infarction undergoing percutaneous coronary intervention
}

Ik Jun Choi ${ }^{1,2}$, Eun Ho Choo ${ }^{2,3^{*}} \mathbb{D}$, Hwa Jung Kim³, Sungmin Lim, Donggyu Moon ${ }^{5}$, Kwan Yong Lee ${ }^{3}$, Byung-Hee Hwang ${ }^{3}$, Chan Joon Kim ${ }^{4}$, Mahn-Won Park ${ }^{6}$, Jong-Min Lee ${ }^{4}$, Chul Soo Park ${ }^{7}$, Hee-Yeol Kim ${ }^{8}$, Ki-Dong Yoo ${ }^{5}$, Doo Soo Jeon ${ }^{1}$, Wook Sung Chung ${ }^{3}$, Min Chul Kim ${ }^{9}$, Myung Ho Jeong ${ }^{9}$, Youngkeun Ahn ${ }^{9}$ and Kiyuk Chang ${ }^{2,3}$

\begin{abstract}
Background: Intensive glycemic control is generally recommended for diabetic patients to reduce complications. However, the role of glycemic control in the mortality in diabetic patients with acute myocardial infarction (AMI) remained unclear.
\end{abstract}

Methods: We selected diabetic patients who measured HbA1c more than 3 times after AMI among 10,719 patients enrolled in the multicenter AMI registry. Patients $(n=1384)$ were categorized into five groups: according to mean HbA1c level: $\leq 6.5 \%,>6.5$ to $\leq 7.0 \%,>7.0$ to $\leq 7.5 \%,>7.5$ to $\leq 8.0 \%$ and $>8.0 \%$. The primary endpoint was all-cause mortality.

Results: During a median follow-up of 6.2 years, the patients with a mean HbA1c of 6.5 to $7.0 \%$ had the lowest all-cause mortality. Compared to patients with mean $\mathrm{HbA1c}$ of 6.5 to $7.0 \%$, the risk of all-cause mortality increased in subjects with mean $\mathrm{HbA} 1 \mathrm{c} \leq 6.5 \%$ (adjusted hazard ratio [HR] 2.00, 95\% confidence interval [Cl] 1.02-3.95) and in those with mean $\mathrm{HbA1c}>8.0 \%$ (adjusted $\mathrm{HR} 3.35,95 \% \mathrm{Cl} 1.78-6.29$ ). In the subgroup analysis by age, the J-curve relationship between mean $\mathrm{HbA} 1 \mathrm{c}$ and all-cause mortality was accentuated in elderly patients (age $\geq 65$ years), while there was no difference in all-cause mortality across the HbA1c groups in younger patients (age $<65$ years).

Conclusions: The less strict glycemic control in diabetic patients with AMI would be optimal for preventing mortality, especially in elderly patients.

Keywords: Diabetes mellitus, Glycated hemoglobin A, Myocardial infarction, Mortality, Hypoglycemia

\footnotetext{
*Correspondence: cmcchu@catholic.ac.kr

${ }^{3}$ Division of Cardiology, Department of Internal Medicine, Seoul St. Mary's

Hospital, College of Medicine, The Catholic University of Korea, 222,

Banpo-daero, Seocho-gu, Seoul 06591, Republic of Korea

Full list of author information is available at the end of the article
}

\section{Background}

Therapeutic strategies to manage blood pressure, lipid, and glucose levels have evolved in the past two decades to reduce the increased risk of macrovascular and microvascular complications in diabetic patients. Although lowering blood pressure and lipid levels were demonstrated original author(s) and the source, provide a link to the Creative Commons licence, and indicate if changes were made. The images or other third party material in this article are included in the article's Creative Commons licence, unless indicated otherwise in a credit line to the material. If material is not included in the article's Creative Commons licence and your intended use is not permitted by statutory regulation or exceeds the permitted use, you will need to obtain permission directly from the copyright holder. To view a copy of this licence, visit http://creativecommons.org/licenses/by/4.0/. The Creative Commons Public Domain Dedication waiver (http://creativecommons.org/publicdomain/zero/1.0/) applies to the data made available in this article, unless otherwise stated in a credit line to the data. 
the benefit for the decrease of macrovascular complications or cardiovascular (CV) events, the relationship between intensive glucose control and CV outcomes is still uncertain. Several randomized controlled trials have investigated the effect of intensive glucose control on $\mathrm{CV}$ disease, which showed positive effects on some CV outcomes, but controversial results for the risk of $\mathrm{CV}$ death and all-cause death [1-5]. However, meta-analyses suggested that an increase of $1 \%$ in the glycated hemoglobin level (HbA1C), reflecting blood glucose levels over the preceding 2 to 3 months, was associated with an $18 \%$ increased risk of $\mathrm{CV}$ events and a $15 \%$ increase in the risk of death [6-8].

The current guidelines recommend that intensive glucose control targeting HbA1c $\leq 6.5 \%$ to $7.0 \%$, but HbA1c targets shall be individualized according to patients' conditions [9-11]. Because intensive glucose control inevitably accompanies an increased risk of experiencing hypoglycemic events associated with increased mortality $[12,13]$. One of the mechanisms of hypoglycemia-induced mortality would be the surge of adrenergic hormones, which may result in the increased risk of vasoconstriction, thrombogenesis, and ventricular arrhythmia [14]. Hypoglycemic events may be more dangerous for patients already diagnosed with $\mathrm{CV}$ disease. Considering that patients with acute myocardial infarction (AMI) should be treated with beta-adrenergic blockers to reduce subsequent $\mathrm{CV}$ events, the hypoglycemic event can increasingly affect diabetic patients with AMI. Though the current guidelines recommend less-stringent HbA1C goals for patients with multiple comorbidities and elderly patients, evidence regarding the HbAlc target for AMI patients with diabetes is limited. Thus, the present study evaluated the effect of intensive glucose control on mortality in diabetic patients with AMI. We also investigated whether the result of intensive glucose control differs according to patients' age.

\section{Methods}

\section{Study population}

The COREA-AMI (CardiOvascular Risk and idEntificAtion of potential high-risk population in Acute Myocardial Infarction) registry was designed to evaluate real-world, long-term clinical outcomes in all patients with AMI. AMI was diagnosed by detecting elevated cardiac biomarkers at least 1 value above the 99th percentile upper reference limit with a temporal rise and fall and at least 1 of the following indications: symptoms of ischemia, new or presumed new significant ST-segment-T wave changes, or new left bundle branch block, development of pathological Q waves on electrocardiography, imaging evidence of new viable myocardium loss or a new regional wall motion abnormality, or an intracoronary thrombus identified by angiography. According to electrocardiography findings, the clinical presentation was divided into ST-segment elevation myocardial infarction (STEMI) and non-ST-segment elevation myocardial infarction (NSTEMI). The COREAAMI I registry has been previously reported and included patients with AMI who underwent percutaneous coronary intervention (PCI) from January 2004 to December 2009. The COREA-AMI II registry included additional patients from January 2010 to August 2014. The current registry comprised updated new clinical and angiographic parameters and evaluated long-term clinical follow-up data for as long as possible until 2019. The study was conducted in compliance with the Declaration of Helsinki regarding investigations in humans. The study protocol was approved by the Institutional Review Board at participating centers. This registry has been registered on ClinicalTrials.gov (study ID: NCT02806102).

Figure 1 outlines the study flow. Of the 10,719 patients in the COREA-AMI registry, 4093 had diabetes mellitus at index hospitalization. Diabetes mellitus was diagnosed if they had diabetes diagnosed by a physician, if they were taking insulin or oral hypoglycemic agents, or if HbA1c $\geq 6.5 \%$ or random glucose $\geq 200 \mathrm{mg} / \mathrm{dL}$ was observed at index hospitalization. We selected 1384 patients who had undergone at least three measurements of HbA1c during follow-up. The patients were categorized into five groups according to mean $\mathrm{HbA1c}$ level during follow-up period in $0.5 \%$ interval: $\leq 6.5 \%,>6.5$ to $\leq 7.0 \%,>7.0$ to $\leq 7.5 \%,>7.5$ to $\leq 8.0 \%$ and $>8.0 \%$.

\section{Study outcomes}

The primary outcome of this analysis was all-cause mortality. The secondary endpoints were cardiovascular death, MI, and stroke. All-cause deaths were attributed to cardiovascular events unless a non-cardiac death could be clearly identified. Recurrent MI was defined as the presence of recurrent symptoms and new electrocardiographic changes compatible with MI or cardiac markers expressed at least two-fold above the normal limit. Stroke was defined as the presence of a new focal neurologic deficit thought to be vascular in origin, with signs or symptoms lasting more than $24 \mathrm{~h}$.

\section{Data collection}

All data were collected on a web-based system after eliminating personal information. Patients' follow-up data, including survival data and clinical event data, were collected through March 31, 2019, via hospital chart reviews and telephone interviews of patients conducted by trained reviewers who were blinded to the study results. Independent reviewers and interventional cardiologists assessed angiographic and procedural data, and 


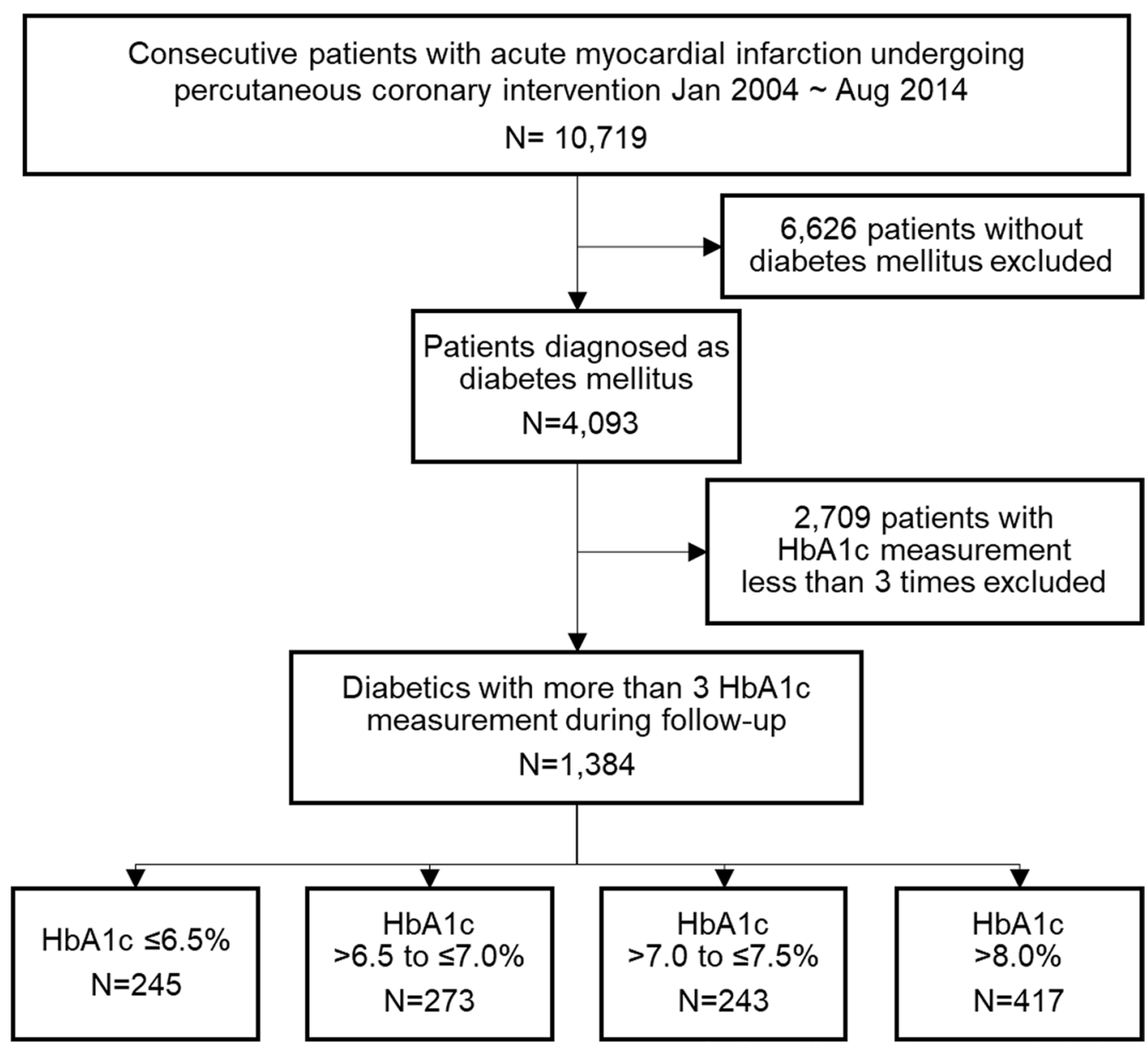

Fig. 1 Study population. Flow chart outlining the selection of the study population

independent research personnel collected baseline clinical, laboratory, and medication data. Clinical events and outcome data were assessed by electrical medical records and telephone conversations. All adverse clinical events of interest were confirmed centrally by the committee of the Cardiovascular Center of Seoul St. Mary's Hospital, Seoul, Republic of Korea. Validation for mortality was performed on the basis of disqualification from the National Health Insurance Service, which is the single government-managed insurance and covers almost all of the nation's population. The final dataset was handled by independent statisticians of the Clinical Research Coordinating Center and sealed with a code by the Clinical Research Associate.

\section{Statistical analysis}

Baseline characteristics were expressed as the mean (SD) and analyzed statistically using ANOVA. Categorical variables were expressed as numbers (and percentages or rates) and analyzed using the Chi-square test or Fisher's exact test, as appropriate. Kaplan-Meier survival curves were constructed to examine the cumulative incidence of primary and secondary outcomes; the incidence rates of outcomes were compared using the log-rank test. A Cox proportional-hazards regression model was used to calculate estimates of relative risk and $95 \%$ confidence intervals (CI) between each of the five groups. In addition to crude hazard ratios (HRs), adjusted HRs were estimated after adjustment for potential confounding factors. The model was adjusted using three models. Model 1 was adjusted for age, sex, and body mass index. Model 2 was adjusted for model 1 plus systolic blood pressure, hypertension, current smoke, chronic kidney disease, and previous stroke. Model 3 was adjusted for model 2 plus the type of MI (STEMI or NSTEMI), left ventricular ejection fraction, low-density lipoprotein cholesterol, Global Registry of Acute Coronary Events (GRACE) score, and complete revascularization. The unadjusted and adjusted hazard ratios for each category of HbA1c were calculated in reference to the $\mathrm{BbA} 1 \mathrm{c}$ of $6.5 \%$ to $7.0 \%$, where 
the hazard ratio was considered as 1 . In addition, nonlinear Cox proportional hazards models were estimated with mean $\mathrm{HbA1c}$ as a continuous variable and with the square of HbA1c. We performed subgroup analysis by age to assess whether the target $\mathrm{HbA1C}$ goal would be less stringent for elderly patients. We divided the study population by the age of 65 years and compared the relationship between HbA1c and mortality. Statistical analyses were conducted with $R$ version 4.0.2 (R Foundation for Statistical Computing, Vienna, Austria). All the statistical testing was 2 -sided. p-value $<0.05$ was considered statistically significant.

\section{Results}

\section{Baseline characteristics}

The mean age of the 1384 patients was $60 \pm 11$ years, and 1012 (73.1\%) were men. During the median followup period of 6.2 years (interquartile range: 4.6-7.9), the median number of HbA1c measurements was 4 (interquartile range: $3-6$ ). The median interval between $\mathrm{HbA1c}$ measurements was 470 days. The mean HbA1c was $7.6 \pm 1.2 \%$ overall. Baseline characteristics of the entire cohort and the patients categorized by HbA1c classification are depicted in Table 1. Patients with lower HbA1c were older and more likely to have hypertension, a history of stroke, higher left ventricular ejection fraction, and lower cholesterol levels. Though patients with lower HbA1c had a lower estimated glomerular filtration rate, the proportion of severe and moderate chronic kidney disease was not different among the groups. Patients with lower HbA1c were less likely to be treated with insulin, metformin, and sulfonylurea. The Geriatric Nutritional Risk Index (GNRI) of patients with $\leq 6.5 \%$, patients with $7-7.5 \%$, and patients with $\mathrm{HbA1c}>8.0 \%$ were similar, and only GNRI of patients with HbA1c $>8.0 \%$ was significantly lower only in compared to that of the patients with $\mathrm{HbA1c}$ of 6.5 to $7.0 \%$. Angiographic findings, including the severity, extent of coronary artery disease, and the degree of stent implantation, were similar among the groups.

\section{Clinical outcomes}

All-cause mortality occurred in 158 (11.4\%) patients. The relationship between $\mathrm{HbA1C}$ and the incidence of allcause mortality followed a J-shaped curve, with increased incidence of all-cause mortality at low and high HbA1c (Table 2, Fig. 2). Patients with a mean HbA1c of $6.5 \%$ to $7.0 \%$ had the lowest all-cause mortality. Cubic regression spline analysis revealed that the adjusted risk of allcause mortality was the lowest for those with a HbA1c of $6.7 \%$ and tended to increase in those with lower HbA1c and higher HbAlc, describing J-curve pattern (Additional file 1: Fig. S1). Compared with the reference group
(HbA1c of $6.5 \%$ to $7.0 \%$ ), the risk of mortality increased twofold in patients with $\mathrm{HbA} 1 \mathrm{c} \leq 6.5 \%$ and by more than threefold in those with HbA1c $>8.0 \%$ after adjustment for covariates of Model 3 (Table 3, Fig. 2).

For the secondary outcomes, cardiovascular death occurred in 111 (8.0\%) patients, 93 (6.7\%) patients experienced myocardial infarction, and 58 (4.2\%) experienced ischemic stroke. Cardiovascular death was increased from in patients with $\mathrm{HbA} 1 \mathrm{c}>7.5 \%$ and $\leq 8.0 \%$ and significantly increased in those with $\mathrm{HbA1c}>8.0 \%$ (adjusted HR 4.24, 95\% CI 2.17-8.27, p < 0.001), but not significantly increased in patients with $\mathrm{HbA1c} \leq 6.5 \%$ (adjusted HR 1.44, 95\% CI 0.65-3.15, p = 0.368) compared to patients with HbA1c of $6.5 \%$ to $7.0 \%$ after full adjustment (Additional file 1: Table S1). There was no significant difference in the rates of myocardial infarction and stroke among groups (Table 2). The risk of the composite of cardiovascular death, myocardial infarction, and stroke was significantly increased only in patients with HbA1c > 8.0\% (adjusted HR 1.59, 95\% CI 1.08-2.34, $\mathrm{p}=0.018$ ) (Additional file 1: Table S2).

\section{Subgroup analysis of the relationship between HbA1c and mortality according to age}

When the patients were divided by 65 years, a bimodal relationship between $\mathrm{HbA1c}$ and all-cause mortality was not observed in patients aged below 65 years but in patients aged 65 years or older. The incidence of mortality was not different in patients below the age of 65 years among HbA1c groups. In contrast, the increase of hazard rates of mortality at low and high $\mathrm{HbA1c}$ remained significant after full adjustment in patients aged 65 years or older. However, the interaction between age and HbA1c was not significant $(\mathrm{p}=0.685)$. The risk of mortality increased threefold in the group with $\mathrm{HbA} 1 \mathrm{c} \leq 6.5 \%$ and sixfold with $\mathrm{HbA} 1 \mathrm{c}>8.0 \%$ in patients aged 65 years or older (Fig. 3). Patients aged 65 years or older were more likely to have lower HbA1c, low body mass index, diagnosis of NSTEMI, history of stroke, lower left ventricular function, lower cholesterol level, worse kidney function, complex coronary disease, and a lower rate of complete revascularization compared to those less than 65 years of age (Additional file 1: Table S3).

\section{Sensitivity analysis to exclude reverse causality}

For the possibility that the higher risks of all-cause deaths in patients with low mean HbA1c levels may be due to reverse causality, we performed sensitivity analyses excluding from primary analyses those individuals who died in the first 1 year after the last HbA1c measurement. Even after excluding 101 patients, the baseline characteristics of patients and the trend of J-curve relationship between the HbA1c and all-cause mortality were 
Table 1 Baseline characteristics of the patients according to the glycated hemoglobin level

\begin{tabular}{|c|c|c|c|c|c|c|}
\hline & $\begin{array}{l}\mathrm{HbA} 1 \mathrm{c} \leq 6.5 \% \\
(\mathrm{~N}=245)\end{array}$ & $\begin{array}{l}6.5 \%<\mathrm{HbA} 1 \mathrm{c} \leq 7.0 \% \\
(\mathrm{~N}=273)\end{array}$ & $\begin{array}{l}7.0 \%<\mathrm{HbA} 1 \mathrm{c} \leq 7.5 \% \\
(\mathrm{~N}=243)\end{array}$ & $\begin{array}{l}7.5 \%<\mathrm{HbA} 1 \mathrm{c} \leq 8.0 \% \\
(\mathrm{~N}=206)\end{array}$ & $\begin{array}{l}\mathrm{HbA} 1 \mathrm{c}>8.0 \% \\
(\mathrm{~N}=417)\end{array}$ & $p$ \\
\hline Mean HbA1c level & $6.2 \pm 0.3$ & $6.8 \pm 0.1$ & $7.3 \pm 0.1$ & $7.7 \pm 0.1$ & $9.0 \pm 0.8$ & $<0.001$ \\
\hline $\begin{array}{l}\text { Number of } \mathrm{HbA} 1 \mathrm{c} \text { meas- } \\
\text { urement }\end{array}$ & $5.0[3.0,7.0]$ & $4.0[3.0,6.0]$ & $5.0[3.0,6.0]$ & $4.0[3.0,6.0]$ & $4.0[3.0,6.0]$ & 0.05 \\
\hline $\begin{array}{l}\mathrm{Hb} \text { A1c measurement } \\
\text { interval, days }\end{array}$ & $447[272,636]$ & $446[340,674]$ & $468[351,671]$ & $512[368,726]$ & $467[344,653]$ & 0.055 \\
\hline $\begin{array}{l}\text { Mean follow-up period, } \\
\text { years }\end{array}$ & $6.3 \pm 2.3$ & $6.5 \pm 2.3$ & $6.6 \pm 2.3$ & $6.3 \pm 2.2$ & $6.4 \pm 2.5$ & 0.798 \\
\hline Age (years) & $62.9 \pm 10.8$ & $60.9 \pm 11.0$ & $61.4 \pm 11.2$ & $59.5 \pm 11.2$ & $58.0 \pm 11.2$ & $<0.001$ \\
\hline Age $\geq 65(\%)$ & $113(46.1)$ & $108(39.6)$ & $109(44.9)$ & $72(35.0)$ & $121(29.0)$ & $<0.001$ \\
\hline Male (\%) & $179(73.1)$ & $211(77.3)$ & $185(76.1)$ & $148(71.8)$ & $289(69.3)$ & 0.147 \\
\hline BMI $\left(\mathrm{kg} / \mathrm{m}^{2}\right)$ & $24.8 \pm 3.2$ & $25.1 \pm 3.1$ & $25.2 \pm 3.3$ & $24.9 \pm 3.2$ & $24.7 \pm 3.4$ & 0.3 \\
\hline Diagnosis (\%) & & & & & & 0.24 \\
\hline STEMI & $128(52.2)$ & $127(46.5)$ & $122(50.2)$ & $104(50.5)$ & $184(44.1)$ & \\
\hline NSTEMI & $117(47.8)$ & $146(53.5)$ & $121(49.8)$ & $102(49.5)$ & $233(55.9)$ & \\
\hline $\begin{array}{l}\text { Cardiac arrest on arrival } \\
(\%)\end{array}$ & $2(0.8)$ & $2(0.7)$ & $0(0.0)$ & $1(0.5)$ & $1(0.2)$ & 0.553 \\
\hline Systolic BP (mmHg) & $130.9 \pm 26.5$ & $134.2 \pm 27.1$ & $131.5 \pm 26.5$ & $132.7 \pm 27.1$ & $130.4 \pm 28.5$ & 0.45 \\
\hline Diastolic BP (mmHg) & $79.7 \pm 16.0$ & $80.5 \pm 15.6$ & $79.9 \pm 17.2$ & $80.2 \pm 17.4$ & $78.9 \pm 17.0$ & 0.749 \\
\hline Heart rate (bpm) & $79.1 \pm 20.8$ & $79.4 \pm 18.5$ & $80.2 \pm 17.4$ & $81.4 \pm 18.0$ & $82.2 \pm 19.8$ & 0.223 \\
\hline Killip class $\geq 3(\%)$ & $223(91.0)$ & $252(92.3)$ & $225(92.6)$ & $182(88.3)$ & $362(86.8)$ & 0.063 \\
\hline Hypertension (\%) & $168(68.6)$ & $157(57.5)$ & $143(58.8)$ & $132(64.1)$ & $228(54.7)$ & 0.005 \\
\hline $\begin{array}{l}\text { Dyslipidemia on drug } \\
\text { treatment (\%) }\end{array}$ & $40(16.3)$ & $53(19.4)$ & $42(17.3)$ & $39(18.9)$ & $70(16.8)$ & 0.853 \\
\hline Current smoker (\%) & $89(36.3)$ & $115(42.1)$ & $95(39.1)$ & $76(36.9)$ & $187(44.8)$ & 0.157 \\
\hline History of MI (\%) & $7(2.9)$ & $4(1.5)$ & $10(4.1)$ & $8(3.9)$ & $14(3.4)$ & 0.432 \\
\hline History of PCI (\%) & $17(6.9)$ & $15(5.5)$ & $13(5.3)$ & $16(7.8)$ & $20(4.8)$ & 0.572 \\
\hline History of stroke (\%) & $23(9.4)$ & $24(8.8)$ & $14(5.8)$ & $6(2.9)$ & $25(6.0)$ & 0.037 \\
\hline History of cancer (\%) & $8(3.3)$ & $10(3.7)$ & $4(1.6)$ & $7(3.4)$ & $9(2.2)$ & 0.545 \\
\hline LVEF, \% & $53.4 \pm 11.0$ & $53.3 \pm 11.0$ & $54.4 \pm 10.4$ & $53.4 \pm 11.0$ & $51.3 \pm 10.5$ & 0.003 \\
\hline $\begin{array}{l}\text { Total cholesterol (mg/ } \\
\mathrm{dL})\end{array}$ & $169.5 \pm 41.2$ & $173.7 \pm 41.9$ & $176.4 \pm 42.2$ & $179.5 \pm 45.3$ & $182.0 \pm 46.6$ & 0.008 \\
\hline Triglyceride (mg/dL) & $129.9 \pm 104.5$ & $141.6 \pm 96.5$ & $153.2 \pm 118.6$ & $156.1 \pm 113.3$ & $161.1 \pm 141.2$ & 0.013 \\
\hline HDL cholesterol (mg/dL) & $40.3 \pm 10.3$ & $39.8 \pm 10.4$ & $39.6 \pm 11.6$ & $39.5 \pm 8.9$ & $39.4 \pm 9.4$ & 0.866 \\
\hline LDL cholesterol (mg/dL) & $105.3 \pm 35.6$ & $108.9 \pm 36.3$ & $108.6 \pm 35.2$ & $112.1 \pm 39.8$ & $113.5 \pm 39.2$ & 0.09 \\
\hline $\mathrm{eGFR}\left(\mathrm{mL} / \mathrm{min} / 1.73 \mathrm{~m}^{2}\right)$ & $73.3[55.1,91.9]$ & $81.6[63.1,95.8]$ & $81.0[60.3,97.1]$ & $78.5[61.4,97.8]$ & $79.9[59.2,99.9]$ & 0.015 \\
\hline Dialysis (\%) & $8(3.3)$ & $4(1.5)$ & $3(1.2)$ & $1(0.5)$ & $9(2.2)$ & 0.237 \\
\hline$e G F R \leq 30(\%)$ & $21(8.6)$ & $18(6.6)$ & $18(7.4)$ & $9(4.4)$ & $27(6.5)$ & 0.495 \\
\hline $30<\mathrm{eGFR} \leq 60(\%)$ & $53(21.6)$ & $38(13.9)$ & $42(17.3)$ & $38(18.4)$ & $77(18.5)$ & 0.244 \\
\hline GRACE score & $\begin{array}{l}139.0[116.0 \\
156.0]\end{array}$ & $133.0[112.0,153.0]$ & $135.0[107.5,158.0]$ & $126.0[109.0,150.8]$ & $\begin{array}{l}133.0[112.0, \\
153.0]\end{array}$ & 0.251 \\
\hline GNRI & $97.8 \pm 8.6$ & $99.7 \pm 16.9$ & $97.9 \pm 7.7$ & $97.4 \pm 8.2$ & $96.3 \pm 8.1$ & $0.002^{\mathrm{a}}$ \\
\hline \multicolumn{7}{|l|}{ Discharge medication } \\
\hline Aspirin (\%) & 244 (99.6) & $266(97.4)$ & $239(98.4)$ & $205(99.5)$ & $412(98.8)$ & 0.204 \\
\hline Clopidogrel (\%) & $213(86.9)$ & $237(86.8)$ & $215(88.5)$ & $181(87.9)$ & $365(87.5)$ & 0.98 \\
\hline $\begin{array}{l}\text { Potent P2Y12 inhibi- } \\
\text { tor (\%) }\end{array}$ & $31(12.7)$ & $36(13.2)$ & $28(11.5)$ & $25(12.1)$ & $52(12.5)$ & 0.986 \\
\hline Statin (\%) & $219(94.4)$ & $239(96.8)$ & $216(96.4)$ & $181(94.3)$ & 375 (96.6) & 0.437 \\
\hline Beta blocker (\%) & $196(92.9)$ & $238(96.0)$ & $209(94.1)$ & $179(95.7)$ & $334(93.3)$ & 0.487 \\
\hline RAS blocker (\%) & $161(65.7)$ & $182(66.7)$ & $167(68.7)$ & $138(67.0)$ & $305(73.1)$ & 0.227 \\
\hline Anticoagulation (\%) & $6(2.4)$ & $9(3.3)$ & $8(3.3)$ & $7(3.4)$ & $11(2.6)$ & 0.95 \\
\hline
\end{tabular}


Table 1 (continued)

\begin{tabular}{|c|c|c|c|c|c|c|}
\hline & $\begin{array}{l}\mathrm{HbA} 1 \mathrm{c} \leq 6.5 \% \\
(\mathrm{~N}=245)\end{array}$ & $\begin{array}{l}6.5 \%<\mathrm{HbA} 1 \mathrm{c} \leq 7.0 \% \\
(\mathrm{~N}=273)\end{array}$ & $\begin{array}{l}7.0 \%<\mathrm{HbA} 1 \mathrm{c} \leq 7.5 \% \\
(\mathrm{~N}=243)\end{array}$ & $\begin{array}{l}7.5 \%<\mathrm{HbA} 1 \mathrm{c} \leq 8.0 \% \\
(\mathrm{~N}=206)\end{array}$ & $\begin{array}{l}\mathrm{HbA} 1 \mathrm{c}>8.0 \% \\
(\mathrm{~N}=417)\end{array}$ & $p$ \\
\hline $\begin{array}{l}\text { Glucose-lowering } \\
\text { treatment (\%) }\end{array}$ & $128(52.2 \%)$ & $172(63.0 \%)$ & $144(59.3 \%)$ & $143(69.4 \%)$ & $294(70.5 \%)$ & $<0.001$ \\
\hline Insulin (\%) & $11(4.5)$ & $19(7.0)$ & $17(7.0)$ & $21(10.2)$ & $57(13.8)$ & $<0.001$ \\
\hline Metformin (\%) & $76(31.1)$ & $117(42.9)$ & $95(39.3)$ & $105(51.5)$ & $193(46.6)$ & $<0.001$ \\
\hline Sulfonylurea (\%) & $51(20.8)$ & $74(27.2)$ & $68(28.1)$ & $75(36.8)$ & $160(38.6)$ & $<0.001$ \\
\hline Thiazolidinedione (\%) & $0(0.0)$ & $0(0.0)$ & $0(0.0)$ & $1(0.5)$ & $2(0.5)$ & 0.498 \\
\hline DPP4 inhibitor (\%) & $10(4.1)$ & $17(6.3)$ & $16(6.6)$ & $13(6.3)$ & $28(6.8)$ & 0.699 \\
\hline a-glucosidase (\%) & $8(3.3)$ & $14(5.2)$ & $14(5.8)$ & $17(8.3)$ & $33(8.0)$ & 0.097 \\
\hline \multicolumn{7}{|l|}{ Angiographic data } \\
\hline Culprit lesion (\%) & & & & & & 0.466 \\
\hline LM/LAD & $128(52.3)$ & $130(47.6)$ & $116(47.7)$ & $106(51.5)$ & $196(47.0)$ & \\
\hline RCA/LCX & $117(47.8)$ & $143(52.4)$ & $127(52.3)$ & $100(48.6)$ & $221(53.0)$ & \\
\hline LM disease (\%) & $21(8.6)$ & $11(4.0)$ & $13(5.3)$ & $13(6.3)$ & $24(5.8)$ & 0.281 \\
\hline $\begin{array}{l}\text { Multivessel disease } \\
\text { (\%) }\end{array}$ & $96(39.2)$ & $106(38.8)$ & 87 (35.8) & $84(40.8)$ & $157(37.6)$ & 0.85 \\
\hline $\begin{array}{l}\text { Complete revasculari- } \\
\text { zation (\%) }\end{array}$ & $179(73.1)$ & $183(67.0)$ & $163(67.1)$ & $146(70.9)$ & $292(70.0)$ & 0.531 \\
\hline Total stent number & $1.7 \pm 0.9$ & $1.6 \pm 0.9$ & $1.7 \pm 0.8$ & $1.6 \pm 1.0$ & $1.7 \pm 1.0$ & 0.299 \\
\hline Mean stent diameter & $3.2 \pm 0.4$ & $3.2 \pm 0.4$ & $3.1 \pm 0.4$ & $3.1 \pm 0.4$ & $3.1 \pm 0.4$ & 0.071 \\
\hline Total stent length & $34.9 \pm 22.8$ & $34.4 \pm 20.5$ & $33.9 \pm 18.4$ & $35.7 \pm 22.5$ & $37.0 \pm 23.1$ & 0.387 \\
\hline
\end{tabular}

Values are reported as $\mathrm{n}(\%)$, mean $\pm \mathrm{SD}$, or median [interquartile range]

HbA1c glycated hemoglobin A, BMI body mass index, STEMI ST-elevation myocardial infarction, NSTEMI non-ST-elevation myocardial infarction, BP blood pressure, $M I$ myocardial infarction, $P C I$ percutaneous coronary intervention, CABG coronary artery bypass surgery, LVEF left ventricular ejection fraction, eGFR estimated glomerular filtration rate, HDL high-density lipoprotein, LDL low-density lipoprotein, GRACE Global Registry of Acute Coronary Events, GNRI Geriatric Nutritional Risk Index, $R A S$ renin angiotensin system blocker, PPAR peroxisome proliferator-activated receptor, DPP4 dipeptidyl peptidase-4, $L M$ left main, $L A D$ left anterior descending artery, $R C A$ right coronary artery, $L C X$ left circumflex artery

${ }^{\mathrm{a}}$ In Bonferroni post hoc analysis, only GNRI of patients with $\mathrm{HbA} 1 \mathrm{c}>8.0 \%$ was significantly lower than that of patients with $\mathrm{HbA} 1 \mathrm{c}$ of 6.5 to $7.0 \%$

Table 2 Clinical outcomes of the patients according to the glycated hemoglobin level

\begin{tabular}{|c|c|c|c|c|c|c|}
\hline & $\mathrm{HbA} 1 \mathrm{c} \leq 6.5 \%$ & $6.5 \%<\mathrm{HbA} 1 \mathrm{c} \leq 7.0 \%$ & $7.0 \%<\mathrm{HbA} 1 \mathrm{c} \leq 7.5 \%$ & $7.5 \%<\mathrm{HbA} 1 \mathrm{c} \leq 8.0 \%$ & $\mathrm{HbA} 1 \mathrm{c}>8.0 \%$ & $p$ \\
\hline All cause death (\%) & $29(51.2)$ & $18(28)$ & $25(39.9)$ & $20(26.1)$ & $66(176.3)$ & 0.004 \\
\hline Cardiovascular death (\%) & $15(26.5)$ & $11(17.1)$ & $15(23.9)$ & $14(18.3)$ & $56(149.6)$ & $<0.001$ \\
\hline Non-cardiovascular death (\%) & $14(24.7)$ & $7(10.9)$ & $10(16)$ & $6(7.8)$ & $10(26.7)$ & 0.172 \\
\hline Myocardial infarction (\%) & $11(19.4)$ & $15(23.3)$ & $17(27.1)$ & $14(18.3)$ & $36(96.2)$ & 0.281 \\
\hline Stroke $(\%)$ & $12(21.2)$ & $12(18.7)$ & $11(17.6)$ & $10(13)$ & $13(34.7)$ & 0.768 \\
\hline $\begin{array}{l}\text { Composite of cardiovascular } \\
\text { death, myocardial infarction, and } \\
\text { stroke }\end{array}$ & $34(60)$ & $39(60.6)$ & $36(57.5)$ & $32(41.7)$ & $90(240.4)$ & 0.033 \\
\hline
\end{tabular}

Values are reported as $\mathrm{n}$ (incidence rate per 1000 person-years)

HbA1c glycated hemoglobin A

maintained in the sensitivity analyses (Additional file 1: Tables S4-S6).

\section{Discussion}

The mean HbA1c level during follow-up of 1348 diabetic patients who underwent PCI for AMI showed a bimodal (J-curve) relationship with all-cause mortality. Compared to patients with $\mathrm{HbAlc}$ in the range of $6.5 \%$ to $7.0 \%$ who had the lowest risk of mortality, the risk of mortality was significantly higher in patients with HbA1c $\leq 6.5 \%$ and those with HbA1c $>8.0 \%$ after adjusting for potential confounding factors. The increased mortality in patients with HbA1c < $6.5 \%$ was driven by both cardiovascular death and non-cardiovascular death, whereas excess mortality in patients with HbA1c $>8.0 \%$ was attributed to high cardiovascular death. Further, the J-curve 

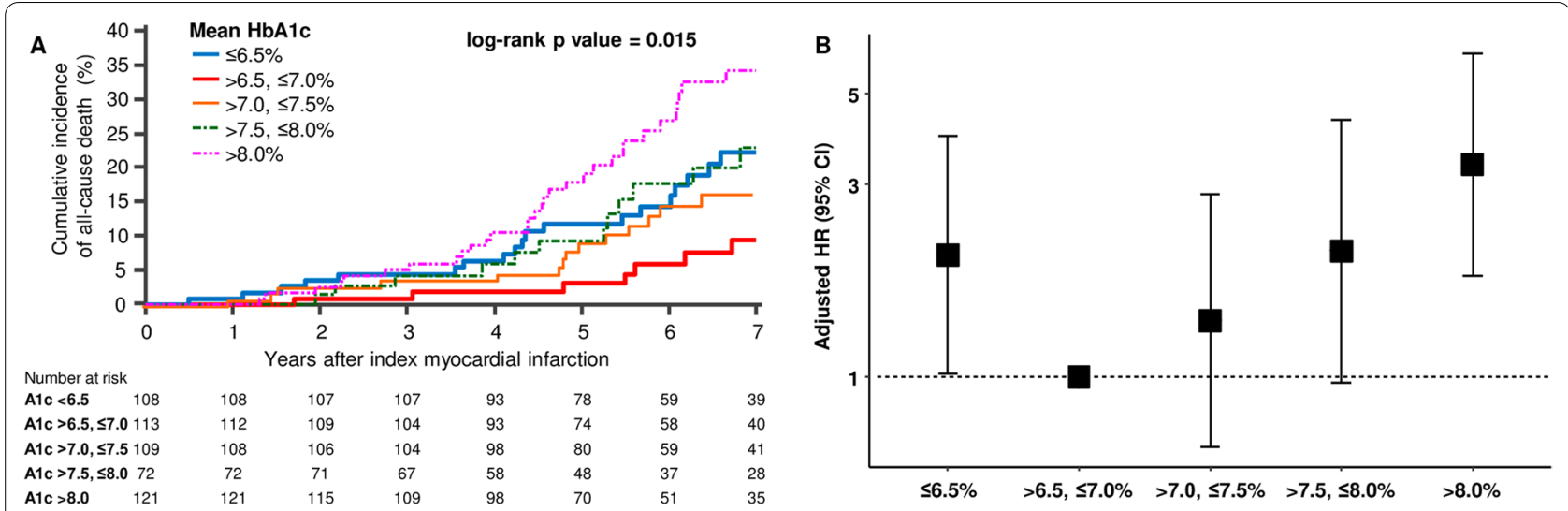

Fig. 2 Incidence and adjusted hazard ratio of all-cause mortality according to HbA1c group. A Kaplan-Meier curve of all-cause mortality according to HbA1c group. B Hazard ratio and 95\% confidence interval by multivariate Cox regression (Model 3: adjustment with age, sex, hypertension, current smoke, chronic kidney disease, previous stroke, the type of myocardial infarction, left ventricular ejection fraction, GRACE score, and complete revascularization) according to HbA1c group. HR hazard ratio, Cl confidence interval

Table 3 Hazard ratios and 95\% Cls of mortality according to the glycated hemoglobin level

\begin{tabular}{|c|c|c|c|c|c|c|c|c|c|c|c|c|}
\hline \multirow[t]{2}{*}{ HbA1c group } & \multicolumn{3}{|c|}{ Unadjusted HR } & \multicolumn{3}{|c|}{ Model 1} & \multicolumn{3}{|c|}{ Model 2} & \multicolumn{3}{|c|}{ Model 3} \\
\hline & HR & $95 \% \mathrm{Cl}$ & $p$ value & HR & $95 \% \mathrm{Cl}$ & $p$ value & HR & $95 \% \mathrm{Cl}$ & $p$ value & $\mathrm{HR}$ & $95 \% \mathrm{Cl}$ & $\mathrm{p}$ value \\
\hline $6.5 \%<\mathrm{HbA} 1 \mathrm{c} \leq 7.0 \%$ & Ref & & & Ref & & & Ref & & & Ref & & \\
\hline $\mathrm{HbA} 1 \mathrm{c} \leq 6.5 \%$ & 2.17 & $1.11-4.24$ & 0.024 & 2.16 & $1.1-4.24$ & 0.025 & 2.09 & $1.02-3.88$ & 0.043 & 2.00 & $1.02-3.95$ & 0.045 \\
\hline $7.0 \%<\mathrm{HbA} 1 \mathrm{c} \leq 7.5 \%$ & 1.61 & $0.8-3.27$ & 0.183 & 1.68 & $0.83-3.41$ & 0.150 & 1.67 & $0.82-3.39$ & 0.156 & 1.38 & $0.67-2.82$ & 0.381 \\
\hline $7.5 \%<\mathrm{HbA} 1 \mathrm{c} \leq 8.0 \%$ & 1.65 & $0.79-3.43$ & 0.181 & 2.01 & $0.96-4.21$ & 0.064 & 2.11 & $1-4.43$ & 0.049 & 2.05 & $0.97-4.33$ & 0.059 \\
\hline $\mathrm{HbA} 1 \mathrm{c}>8.0 \%$ & 2.64 & $1.44-4.85$ & 0.002 & 3.60 & $1.93-6.72$ & $<0.001$ & 3.51 & $1.88-6.56$ & $<0.001$ & 3.35 & $1.78-6.29$ & $<0.001$ \\
\hline
\end{tabular}

Model 1: Hazard ratios categorized HbA1c adjusted by age, sex, and body mass index. Model 2: Hazard ratios categorized HbA1c adjusted by model 1 plus systolic blood pressure, hypertension, current smoke, chronic kidney disease, and previous stroke. Model 3: Hazard ratios categorized HbA1c adjusted by model 2 plus the type of myocardial infarction, left ventricular ejection fraction, low-density lipoprotein cholesterol, GRACE score, and complete revascularization. The C-index of models was 0.764 (95\% confidence interval [Cl] 0.723-0.805), 0.800 (95\% Cl 0.764-0.837), and $0.825(95 \% \mathrm{Cl} 0.791-0.859)$ for models 1,2 , and 3, respectively

$\mathrm{HbA1c}$ glycated hemoglobin A, HR hazard ratio, $\mathrm{Cl}$ confidence interval, Ref. reference

relationship was more robust in elderly patients (age $\geq 65$ years) than younger patients (age $<65$ years).

Glycemic control is fundamental to diabetes management. Meanwhile, the influence of intensive glycemic control on macrovascular complications (myocardial infarction, stroke, and peripheral artery disease) and mortality is disputed. Large randomized controlled trials investigating intensive versus standard glycemic control and vascular outcomes did not show any benefit of intensive glycemic control $[15,16]$. A single study found that intensive control increased mortality [5]. The randomized controlled trials did not enroll patients in the acute phase of $\mathrm{CV}$ disease but only patients with a history of $\mathrm{CV}$ disease. The association between glycemic control and CV outcome after AMI, a very high-risk disease, is unclear. Several observational studies were performed to elucidate the relationship between glycemic control and $\mathrm{CV}$ outcomes in diabetic patients who underwent PCI.
Poor glycemic control was associated with an increased risk of mortality (HbA1c > 10\%) [17] and CV events $($ HbA1c $>7 \%)$ [18]. A study reported that stringent glycemic control (HbA1c < 6.5\%) was associated with the risk of cardiovascular death or sudden death after PCI [19]. However, the proportion of patients with AMI was $10-20 \%$ in those previous studies. The effect of adverse events due to intensive and poor glycemic control on patients with coronary artery disease can be pronounced in patients with AMI. Furthermore, two studies used baseline pre-procedural $\mathrm{HbA} 1 \mathrm{c}$, which partially reflects the glycemic control during the follow-up period after PCI. Our study used mean HbA1c levels during longterm follow-up of AMI patients. We demonstrated that both poor and stringent glycemic control was associated with increased mortality in AMI patients.

It is well known that better glycemic control (target $\mathrm{HbA} 1 \mathrm{c}<7 \%$ ) significantly reduces the rates of 


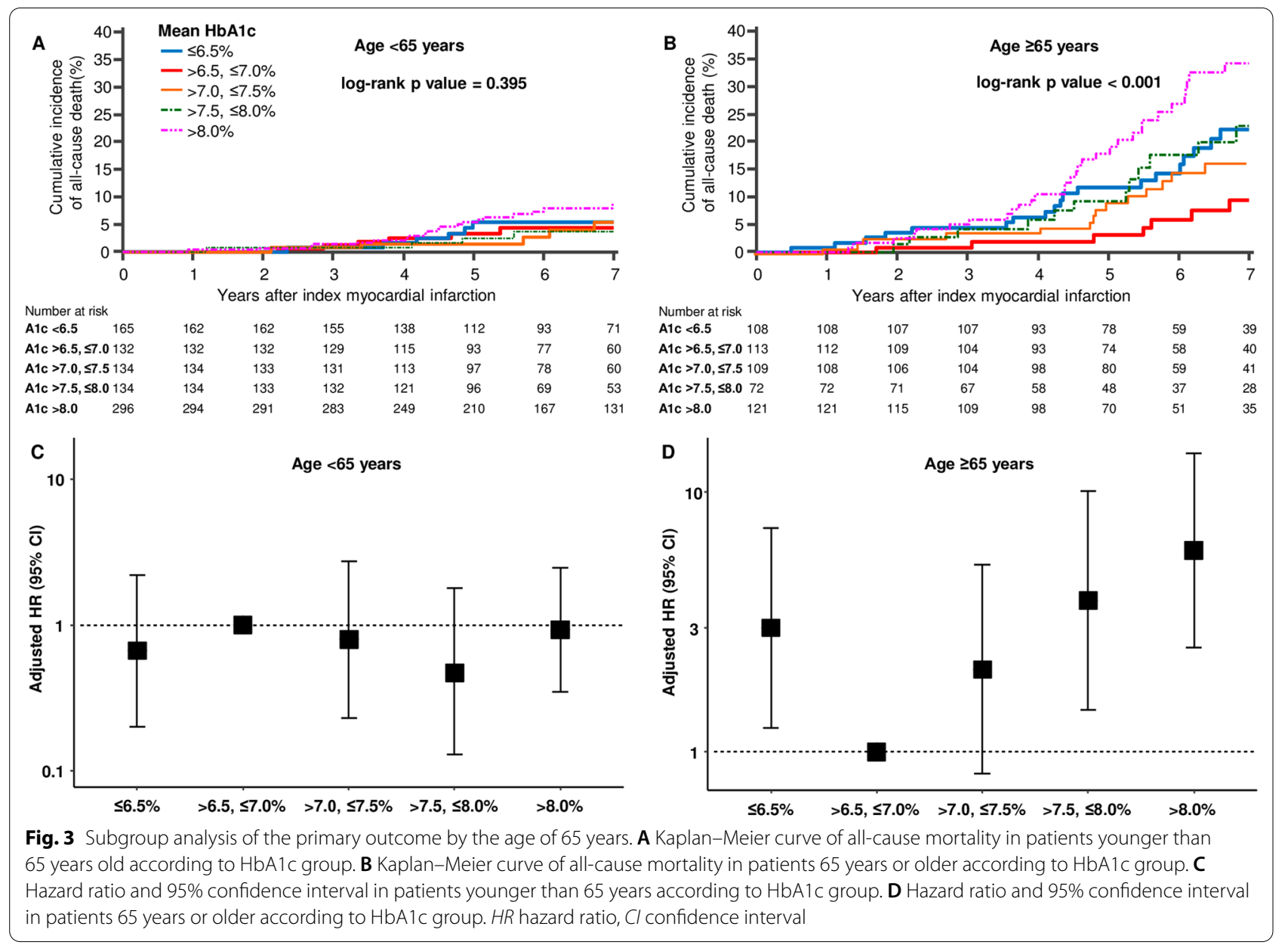

development and progression of microvascular (retinopathy, neuropathy, and diabetic kidney disease) complications [20]. Other analyses also suggest that further lowering of HbA1c from 7 to $6 \%$ is associated with further reduction in the risk of microvascular complications, although the absolute risk reductions become much smaller [11]. To prevent microvascular complications of diabetes, controlling HbA1c $\leq 6.5 \%$ is justified by adequate evidence as a treatment target for patients with a low risk of hypoglycemia. Whereas, subgroup analyses of the VADT study suggest that the potential risks of intensive glycemic control may outweigh its benefits in higher-risk patients [21]. Patients with advanced atherosclerosis or advanced age/frailty may benefit from less aggressive targets [22].

Another characteristic feature of our study was that non-cardiovascular death, as well as cardiovascular death, tended to be high in patients with low mean HbA1c. Other studies have reported higher cancer or non-specific mortality in patients with severe hypoglycemia [13]. There is likely to be a shared underlying cause of both hypoglycemia and mortality, such as diminished physiologic reserve. Since the rate of glucose-lowering treatment was lower in patients with low mean HbA1c in our study, the diminished physiologic reserve in those with low mean HbA1c might have caused high mortality. However, the degree of malnutrition of patients with low mean HbA1c was similar to that of patients with high mean HbA1c. Moreover, we could not observe the reverse causality between $\mathrm{HbA} 1 \mathrm{c}$ and all-cause mortality in the sensitivity analysis. The mechanisms directly linking low mean $\mathrm{HbA} 1 \mathrm{c}$ to non-cardiovascular deaths are unclear.

Given the substantially increased risk of hypoglycemia in diabetic patients with CV disease and in elderly patients, the risks of lower glycemic targets may outweigh the potential benefits in terms of microvascular complications in these patients. In this study, we compared mortality in two groups categorized by the age of 65 years. The differences in mortality risk according to glycemic control were blunted in the younger patients (age $<65$ years). The neutral effect of glycemic control 
on mortality in younger patients was also observed in the UKPDS 33 study, which showed no difference in CV outcome between intensive glycemic control and diet control in diabetic patients with an average age of 53 years [23]. Stringent glycemic control ( $\mathrm{HbA1c}<6.5 \%)$ in young AMI patients would be safe and necessary to prevent long-term microvascular and macrovascular complications [24]. Conversely, the association between low and high mean HbA1c and increased all-cause mortality was prominent in elderly patients (age $\geq 65$ years). A recent study of the GERODIAB trial has reported that lower mean $\mathrm{HbA1c}$ was associated with lower mortality in diabetic patients aged 70 years and older [25]. However, a more extensive registry study enrolled 27,965 patients older than 50 years and showed a similar J-curve relationship between mean HbA1c and mortality [26]. Another observational study involving 71,092 patients older than 60 years old also found a J-curve relationship between HbA1c and mortality [27]. The ACCORD trial comparing glycemic control in diabetic patients with a mean age of 62 years was halted early due to increased mortality rate in the intensive (HbA1c $<6 \%)$ compared with the standard treatment arm (HbA1c 7.0-7.9\%) with a similar increase in cardiovascular deaths [2]. Severe hypoglycemia was significantly more likely in patients under intensive glycemic control. Our study suggested that glycemic control targeting HbA1c of $6.5-7.0 \%$ would be ideal for preventing future complications in elderly patients, consistent with the current practice guideline $[9,11]$. The mortality findings and the relatively intense efforts required to achieve near euglycemia should be considered when setting glycemic targets in elderly patients. Since we demonstrated a differential effect of intensive glycemic control on mortality according to age, glycemic control after AMI should be individualized according to age or the presence of multiple comorbidities. Further studies are needed under detailed clinical settings.

HbA1c is the metric used to date in clinical trials demonstrating the benefits of improved glycemic control and has an excellent correlation with the mean glucose level. However, the HbA1c test is an indirect measure of average glycemia and is subject to limitations. Conditions such as recent blood transfusion and end-stage kidney disease may result in discrepancies between the HbA1c result and the patient's true mean glycemia [11]. In patients with AMI, clinically relevant bleeding requiring transfusion is frequent within the 1st year after PCI. We used more than three measurements with an interval of 1.3 years to minimize the effect of possible transfusion on the HbA1c level early after PCI. Our cohort included a few patients undergoing dialysis, which was not different among the HbA1c groups.
This study has several limitations. First, as an observational study, we cannot conclude that the observed associations were causal. Unmeasured confounders may affect our results. Despite a relatively small number of patients enrolled, we adjusted with known confounding factors for the mortality after AMI. Second, new hypoglycemic agents such as glucagon-like peptide 1 receptor agonist and sodium-glucose cotransporter 2 inhibitors were not prescribed for our patient population at discharge. We enrolled patients who underwent PCI until the year of 2014, when those medications were not available. Treatment with new hypoglycemic agents lowered $\mathrm{HbA} 1 \mathrm{c}$ by $0.4-0.5 \%$ of HbA1c and demonstrated the mortality benefit in recent randomized trials [28, 29]. Further studies are required to assess whether the J-Curve relationship between HbA1c and mortality was maintained after using new hypoglycemic agents. Third, we analyzed 1384 patients from 4093 diabetic patients, raising concerns of possible selection bias and reducing study generalizability. Baseline characteristics between included and excluded diabetic patients were compared in the Additional file 1: Table S7. Excluded patients had higher risk characteristics such as older ages, higher Killip class, more co-morbidities, and lower left ventricular systolic function. Excluded patients are those at a higher risk of death than included patients. The shorter followup period of excluded patients may not be suitable for examining the effect of long-term glycemic control in this study. Fourth, HbA1c was measured irregularly and with wide intervals. However, the measurement interval was not significantly different among the HbAlc groups. The mean HbA1c level of our study reflects the values over a median of 3 years. Our study may represent the association between long-term glycemic control and long-term mortality in AMI patients with diabetes.

\section{Conclusions}

Mean HbA1c levels was associated with a J-curve relationship with all-cause mortality during long-term follow-up of diabetic patients with AMI. The mortality rate was the lowest in patients with $\mathrm{HbA1C}$ of $6.5-7.0 \%$ and increased when $\mathrm{HbA} 1 \mathrm{c}$ was $6.5 \%$ or less and higher than $8.0 \%$. The J-curve relationship between mean HbA1c and mortality was more robust in elderly patients.

\section{Abbreviations}

AMI: Acute myocardial infarction; HbA1c: Glycated hemoglobin; HR: Hazard ratio; Cl: Confidence interval; CV: Cardiovascular; STEMI: ST-segment elevation myocardial infarction; NSTEMI: Non-ST-segment elevation myocardial infarction; PCI: Percutaneous coronary intervention; GRACE: Global registry of acute coronary events. 


\section{Supplementary Information}

The online version contains supplementary material available at https://doi. org/10.1186/s12933-021-01428-x.

Additional file 1: Table S1. Hazard ratios and 95\% Cls of cardiovascular mortality according to the glycated hemoglobin level. Table S2. Hazard ratios and $95 \%$ Cls of the composite of cardiovascular mortality, myocardial infarction, and stroke according to the glycated hemoglobin level. Table S3. Baseline characteristics of the patients according to age. Table S4. Baseline characteristics of the patients according to the glycated hemoglobin level after excluding individuals who died in the first 1 years after the last $\mathrm{HbA1} \mathrm{c}$ measurement. Table S5. Hazard ratios and $95 \% \mathrm{Cls}$ of mortality according to the glycated hemoglobin level in patients after excluding individuals who died in the first 1 year after the last $\mathrm{HbA} 1 \mathrm{c}$ measurement. Table S6. Hazard ratios and $95 \% \mathrm{Cls}$ of mortality according to the glycated hemoglobin level in patients after exclusion according to age. Table S7. Baseline characteristics of diabetic patients who were excluded from this study and included in this study. Figure S1. Cubic spline curve showing the hazard of all-cause mortality according to mean HbA1c.

\section{Acknowledgements}

The authors thank all participants and all investigators in the COREA-AMI registry.

\section{Authors' contributions}

Conceptualization: IJC, SL and EHC; Data collection and analysis: HJK, DM, KYL, BHH, CJK, M-WP, J-ML, CSP, H-YK, K-DY and DSJ; Investigation: EHC, IJC, KYL, MCK and HWY; Writing — original draft preparation: IJC, EHC, YA and KC; Review and editing: B-HH, CJK and MCK; Supervision: WSC, MHJ, YA and KC. All authors read and approved the final manuscript.

\section{Funding}

None.

\section{Availability of data and materials}

The data of this study may be available on reasonable request to the corresponding author.

\section{Declarations}

\section{Ethics approval and consent to participate}

This study protocol was reviewed and approved by the institutional review board of each participating hospital. All patients provided written informed consent for participation in the registry.

\section{Consent for publication}

Not applicable.

\section{Competing interests}

All authors declare that they have no conflicts of interest regarding the contents of this article.

\section{Author details}

'Division of Cardiology, Department of Internal Medicine, Incheon St. Mary's Hospital, College of Medicine, The Catholic University of Korea, Seoul, Republic of Korea. ${ }^{2}$ Catholic Research Institute for Intractable Cardiovascular Disease (CRID), College of Medicine, The Catholic University of Korea, Seoul, Republic of Korea. ${ }^{3}$ Division of Cardiology, Department of Internal Medicine, Seoul St. Mary's Hospital, College of Medicine, The Catholic University of Korea, 222, Banpo-daero, Seocho-gu, Seoul 06591, Republic of Korea. ${ }^{4}$ Division of Cardiology, Department of Internal Medicine, Uijeongbu St. Mary's Hospital, College of Medicine, The Catholic University of Korea, Seoul, Republic of Korea. ${ }^{5}$ Division of Cardiology, Department of Internal Medicine, St Vincent's Hospital, College of Medicine, The Catholic University of Korea, Suwon, Republic of Korea. ${ }^{6}$ Division of Cardiology, Department of Internal Medicine, Daejeon St. Mary's Hospital, College of Medicine, The Catholic University of Korea, Daejeon, Republic of Korea. ${ }^{7}$ Division of Cardiology, Department of Internal
Medicine, Yeouido St. Mary's Hospital, College of Medicine, The Catholic University of Korea, Seoul, Republic of Korea. ${ }^{8}$ Division of Cardiology, Department of Internal Medicine, Bucheon St. Mary's Hospital, College of Medicine, The Catholic University of Korea, Seoul, Republic of Korea. ${ }^{9}$ Division of Cardiology, Department of Internal Medicine, Chonnam National University Hospital, Chonnam National University School of Medicine, Gwangju, Republic of Korea.

Received: 21 October 2021 Accepted: 4 December 2021

Published online: 15 December 2021

\section{References}

1. DM Nathan PA Cleary JYC Backlund SM Genuth JM Lachin TJ Orchard P Raskin BA Zinman 2005 Intensive diabetes treatment and cardiovascular disease in patients with type 1 diabetes N Engl J Med 3532526432653

2. RR Holman SK Paul MA Bethel DR Matthews HAW Neil 2008 10-year follow-up of intensive glucose control in type 2 diabetes N Engl J Med 3591515771589

3. RA Hayward PD Reaven WL Wiitala GD Bahn DJ Reda L Ge M McCarren WC Duckworth NV Emanuele 2015 Follow-up of glycemic control and cardiovascular outcomes in type 2 diabetes N Engl J Med 372232197 2206

4. HC Gerstein ME Miller RP Byington DC Goff Jr JT Bigger JB Buse WC Cushman S Genuth F Ismail-Beigi RH Grimm Jr 2008 Effects of intensive glucose lowering in type 2 diabetes N Engl J Med 3582425452559

5. HC Gerstein ME Miller S Genuth F Ismail-Beigi JB Buse DC Goff Jr JL Probstfield WC Cushman HN Ginsberg JT Bigger 2011 Long-term effects of intensive glucose lowering on cardiovascular outcomes N Engl J Med 3649818828

6. Y Zhang G Hu Z Yuan L Chen 2012 Glycosylated hemoglobin in relationship to cardiovascular outcomes and death in patients with type 2 diabetes: a systematic review and meta-analysis PLoS ONE 78 e42551

7. KK Ray SRK Seshasai S Wijesuriya R Sivakumaran S Nethercott D Preiss S Erqou N Sattar 2009 Effect of intensive control of glucose on cardiovascular outcomes and death in patients with diabetes mellitus: a meta-analysis of randomised controlled trials Lancet 373967717651772

8. E Selvin S Marinopoulos G Berkenblit T Rami FL Brancati NR Powe SH Golden 2004 Meta-analysis: glycosylated hemoglobin and cardiovascular disease in diabetes mellitus Ann Intern Med 1416421431

9. F Cosentino PJ Grant V Aboyans CJ Bailey A Ceriello V Delgado M Federici G Filippatos DE Grobbee TB Hansen 20202019 ESC guidelines on diabetes, pre-diabetes, and cardiovascular diseases developed in collaboration with the EASD Eur Heart J 412255323

10. AJ Garber Y Handelsman G Grunberger D Einhorn MJ Abrahamson JI Barzilay L Blonde MA Bush RA DeFronzo JR Garber 2020 Consensus statement by the American Association of clinical Endocrinologists and American College of Endocrinology on the comprehensive type 2 diabetes management algorithm—2020 executive summary Endocr Pract 261 107139

11. G Targets 2021 Standards of medical care in diabetes-2021 Diabetes Care 44 Suppl 1573 s84

12. S Zoungas A Patel I Chalmers BE Galan de Q Li L Billot M Woodward T Ninomiya B Neal S MacMahon 2010 Severe hypoglycemia and risks of vascular events and death N Engl J Med 3631514101418

13. AK Lee B Warren CJ Lee JW McEvoy K Matsushita ES Huang AR Sharrett J Coresh E Selvin 2018 The association of severe hypoglycemia with incident cardiovascular events and mortality in adults with type 2 diabetes Diabetes Care 411104111

14. SY Choi SH Ko 2021 Severe hypoglycemia as a preventable risk factor for cardiovascular disease in patients with type 2 diabetes mellitus Korean J Intern Med 362263270

15. A Patel S MacMahon J Chalmers B Neal L Billot M Woodward M Marre M Cooper P Glasziou D Grobbee 2008 Intensive blood glucose control and vascular outcomes in patients with type 2 diabetes N Engl J Med 35824 25602572

16. W Duckworth C Abraira T Moritz D Reda N Emanuele PD Reaven FJ Zieve J Marks SN Davis R Hayward 2009 Glucose control and vascular complications in veterans with type 2 diabetes N Engl J Med 3602129139

17. PK Sharma S Agarwal SG Ellis SS Goel L Cho EM Tuzcu AM Lincoff SR Kapadia 2014 Association of glycemic control with mortality in patients 
with diabetes mellitus undergoing percutaneous coronary intervention Circ Cardiovasc Interv 74503509

18. JK Hwang SH Lee YB Song J Ahn K Carriere MJ Jang TK Park SH Choi JH Yang JH Choi 2017 Glycemic control status after percutaneous coronary intervention and long-term clinical outcomes in patients with type 2 diabetes mellitus Circ Cardiovasc Interv 104111

19. T Funamizu H Iwata Y Nishida K Miyosawa S Doi Y Chikata J Shitara H Endo HWada R Naito 2020 Increased risk of cardiovascular mortality by strict glycemic control (pre-procedural $\mathrm{HbA1c}<65 \%$ ) in Japanese medically-treated diabetic patients following percutaneous coronary intervention: a 10-year follow-up study Cardiovasc Diabetol 191112

20. N Laiteerapong SA Ham Y Gao HH Moffet JY Liu ES Huang AJ Karter 2019 The legacy effect in type 2 diabetes: impact of early glycemic control on future complications (The Diabetes \& Aging Study) Diabetes Care 423 416426

21. WC Duckworth C Abraira TE Moritz SN Davis N Emanuele S Goldman R Hayward GD Huang JB Marks PD Reaven 2011 The duration of diabetes affects the response to intensive glucose control in type 2 subjects: the VA Diabetes Trial J Diabetes Complicat 256355361

22. FM Turnbull C Abraira RJ Anderson RP Byington JP Chalmers WC Duckworth GW Evans HC Gerstein RR Holman TE Moritz 2009 Intensive glucose control and macrovascular outcomes in type 2 diabetes Diabetologia 521122882298

23. UK Prospective Diabetes Study (UKPDS) Group 1998 Effect of intensive blood-glucose control with metformin on complications in overweight patients with type 2 diabetes (UKPDS 34) Lancet 3529131854865

24. A Rawshani A Rawshani S Franzn N Sattar B Eliasson A-M Svensson B Zethelius M Miftaraj DK McGuire A Rosengren 2018 Risk factors, mortality, and cardiovascular outcomes in patients with type 2 diabetes N Engl J Med 3797633644

25. J Doucet C Verny B Balkau AJ Scheen B Bauduceau 2018 Haemoglobin A1c and 5-year all-cause mortality in French type 2 diabetic patients aged 70 years and older: the GERODIAB observational cohort Diabetes Metab 446465472

26. CJ Currie JR Peters A Tynan M Evans RJ Heine OL Bracco T Zagar CD Poole 2010 Survival as a function of HbA1c in people with type 2 diabetes: a retrospective cohort study Lancet 3759713481489

27. ES Huang JY Liu HH Moffet PM John AJ Karter 2011 Glycemic control, complications, and death in older diabetic patients: the diabetes and aging study Diabetes Care 34613291336

28. SP Marso GH Daniels K Brown-Frandsen P Kristensen JFE Mann MA Nauck SE Nissen S Pocock NR Poulter LS Ravn 2016 Liraglutide and cardiovascular outcomes in type 2 diabetes N Engl J Med 3754311322

29. B Zinman C Wanner JM Lachin D Fitchett E Bluhmki S Hantel M Mattheus T Devins OE Johansen HJ Woerle 2015 Empagliflozin, cardiovascular outcomes, and mortality in type 2 diabetes N Engl J Med 373222117 2128

\section{Publisher's Note}

Springer Nature remains neutral with regard to jurisdictional claims in published maps and institutional affiliations.

Ready to submit your research? Choose BMC and benefit from:

- fast, convenient online submission

- thorough peer review by experienced researchers in your field

- rapid publication on acceptance

- support for research data, including large and complex data types

- gold Open Access which fosters wider collaboration and increased citations

- maximum visibility for your research: over $100 \mathrm{M}$ website views per year

At BMC, research is always in progress.

Learn more biomedcentral.com/submissions 